\title{
Integrating the Gridiron
}





\title{
Integrating the Gridiron
}

\author{
Black Civil Rights and \\ American College Football
}

LANE DEMAS

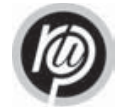

RUTGERS UNIVERSITY PRESS 
Demas, Lane.

Integrating the gridiron : Black Civil Rights and American college football / Lane Demas.

p. cm.

Includes bibliographical references and index.

ISBN 978-O-8I35-474I-I (hardcover : alk. paper)

I. Football-United States-History. 2. College sports-United States-History.

3. Discrimination in sports-United States. 4. Racism in sports-United States.

5. African American athletes-Social conditions. 6. Civil rights movementsHistory. I. Title.

GV959.5.U6D46 2010

796.332'630973-dc22

2009025372

A British Cataloging-in-Publication record for this book is

available from the British Library.

Copyright ( 2010 by Lane Demas

All rights reserved

No part of this book may be reproduced or utilized in any form or by any means, electronic or mechanical, or by any information storage and retrieval system, without written permission from the publisher. Please contact Rutgers University Press, IOo Joyce Kilmer Avenue, Piscataway, NJ 08854-8099. The only exception to this prohibition is "fair use" as defined by U.S. copyright law.

Visit our Web site: http://rutgerspress.rutgers.edu

Manufactured in the United States of America 
For Jennifer 
